\title{
A systematic review of specialist inpatient dementia care services versus standard inpatient dementia care in acute hospitals
}

\author{
B. M. S. McCausland ${ }^{1,2}$ (D) H. P. Patel ${ }^{3,4,5,6} \cdot$ J. Amin $^{1,2} \cdot$ D. S. Baldwin ${ }^{1} \cdot$ K. Loughran ${ }^{1} \cdot$ V. C. Osman-Hicks ${ }^{1,2}$
}

Received: 28 May 2018 / Accepted: 4 August 2018 / Published online: 26 September 2018

(c) The Author(s) 2018

\begin{abstract}
Background Specialist inpatient dementia units (SIDU) have been developed to address adverse outcomes often experienced by people living with dementia admitted to acute hospitals. However, the evidence base of their effectiveness remains limited. Aim To review the current literature to establish the comparative effectiveness of acute hospital SIDU vs. standard ward care (SWC).

Methods We did an online search of 12 biomedical databases from inception to 31st October 2017. Studies of inpatients with any form of dementia in acute hospitals, published in English language peer-reviewed journals, using experimental, observational or qualitative study designs, comparing SIDU with SWC and which measured any qualitative or quantitative outcome of the patient or carer experience were included in the search criteria. We used a standardised data extraction and appraisal form.

Results Three of 46 full-text studies evaluated were suitable for analysis. Due to study heterogeneity, pooled odds ratios were only possible for mortality [OR 1.06 (CI 1.0-1.4)]. Otherwise, a narrative synthesis was performed. Although quantitative measures of length of stay, mortality and behavioural and psychiatric symptoms of dementia are not significantly lower, SIDU are associated with greater patient and carer satisfaction, reduced readmission rates, more accurate and comprehensive assessment processes, documentation of resuscitation decisions, and increased rates of discharge to the patient's own home. Conclusions Although SIDU may be associated with improved care outcomes, the current evidence of their effectiveness is markedly limited. Further research and service evaluation of SIDU as a method for providing high-quality dementia care in acute NHS Trusts is needed. PROSPERO: CRD42017078364.
\end{abstract}

Keywords Dementia $\cdot$ Acute hospital $\cdot$ Specialist dementia ward

B. M. S. McCausland

bmccausland@doctors.org.uk

1 University of Southampton Faculty of Medicine (Clinical and Experimental Sciences), University Hospital Southampton NHS Foundation Trust, Southampton, UK

2 Department of Psychological Medicine, University Hospital Southampton NHS Foundation Trust, Southampton, UK

3 Academic Geriatric Medicine, University of Southampton, University Hospital Southampton NHS Foundation Trust, Southampton, UK

4 Medicine for Older People, University Hospital Southampton NHS Foundation Trust, Southampton, UK

5 Medical Research Council Lifecourse Epidemiology Unit, University Hospital Southampton NHS Foundation Trust, Southampton, UK

6 National Institute for Health Research Southampton Biomedical Research Centre, University Hospital Southampton NHS Foundation Trust, Southampton, UK

\section{Introduction}

Dementia represents a significant and increasing health and social care problem in the context of an ageing population $[1,2]$. Approximately 850,000 people in the UK live with dementia, costing the UK economy an estimated $£ 26$ billion annually [3,4]. Recent data indicate that $86.7 \%$ of patients aged over 75 admitted to UK NHS Trusts for longer than $72 \mathrm{~h}$ were identified as potentially having dementia [5]. Acute hospital admission for patients living with dementia is associated with adverse outcomes from increased length of stay (LOS), morbidity and mortality [6]. The continued assessment and improvement of NHS dementia care is therefore necessary [7].

Multidisciplinary, specialist inpatient dementia units (SIDU) have been developed within acute Trusts for patients with dementia and concomitant acute medical illness, 
whose needs are more complex. Their aim is to increase patient dignity and autonomy with person-centred care [8] provided by staff from both psychiatric and geriatric care backgrounds, trained in managing the behavioural and psychological symptoms of dementia (BPSD) and delirium [9]. These symptoms are often difficult to identify and manage for untrained staff, particularly within the pressured environment of acute hospitals $[10,11]$. If SIDU can reduce LOS by 1 week per patient, the NHS could save up to $£ 80$ million yearly [12].

The aim of this systematic review was to determine whether acute hospital SIDU are effective when compared with standard inpatient ward care (SWC) in improving outcomes for patients living with dementia.

\section{Methods}

\section{Search strategy and selection criteria}

We attempted to locate all peer-reviewed published studies meeting the selection criteria: (1) included men and/or women of any age with any form of dementia, (2) presented the results of peer-reviewed English language research using the following study designs: experimental studies (e.g., randomised controlled trials, non-randomised controlled trials, parallel group studies), before and after studies, interrupted time series studies, case note reviews, cohort studies, case-control studies, cross-sectional studies, case studies, case series, or any qualitative design (e.g., in-depth interviews, focus groups); (3) included participants who were inpatients of an acute hospital; (4) compared SIDU with SWC; (5) measured qualitative or quantitative outcome measures of patient and/or carer experience of the hospital stay. PRISMA reporting guidelines were followed [13, 14]. PROSPERO registration: CRD42017078364.

General discussion papers, comments, letters, book chapters, single case studies, national reports and published conference abstracts were excluded. As there are no gold diagnostic standards aside from post mortem examination, searches were not restricted to studies that used a validated dementia diagnostic method. If stated, the method of assessing dementia was recorded. As we were focusing on acute Trusts in the UK and Ireland, we did not include non-English language studies. If multiple eligible publications from the same study were identified, the one with the largest sample size was included to minimise duplication.

The search strategy comprised (1) electronic searches of 12 biomedical databases (Cochrane, Medline, Embase, Web of Science, Psychinfo, Health Management Information Consortium, British Nursing Index, Cumulative Index to Nursing and Allied Health Literature, Science Direct, Allied and Complementary Medicine Database, Health Business
Elite and PubMed), from their inception to 31st October 2017; (2) citation tracking by manual reference list screening of included studies; (3) expert recommendations (Professors Rowan Harwood and Sube Bannerjee).

\section{Search terms}

Dementia search terms were adapted from a Cochrane systematic review [15]. These were combined with MESH subject heading terms for dementia and health care services, then limited to acute hospitals or inpatient settings, whichever yielded most results, "Appendix 1: Search terms for replication of review".

\section{Data extraction and quality appraisal}

Identified abstracts were downloaded to Endnote $\odot$ software (Thompson Reuters, Version X7) and assessed against the inclusion criteria. A random selection of $10 \%$ of the abstracts was screened independently as a quality check. Potentially eligible studies were downloaded and evaluated against a standardised inclusion checklist. A standardised data extraction form was then used ("Appendix 2: Checklist and data extraction form"). Excluded references were categorised by the primary reason for exclusion. If necessary, the corresponding authors were contacted for clarification or raw data.

Two reviewers independently methodologically assessed the included studies using a standardised appraisal form with a maximum score of 40, developed by Trevillion et al. using criteria adapted from validated tools [16-18] ("Appendix 3: Quality appraisal form"). The overall study quality was reported for all included studies.

\section{Data analysis}

Descriptive analyses were conducted to summarise the included studies. Forest plots were generated using primary data extracted from the studies using DistillerSR Forest Plot Generator from Evidence Partners. Studies that scored poorly in domains relating to bias were not included in the meta-analysis. Funnel plots for detecting publication bias, Cochrane's $I^{2}$ statistic for quantification of study heterogeneity and meta-analyses were not performed as not enough studies met the inclusion criteria.

\section{Results}

The results of the study selection strategy and reasons for exclusion are presented in Fig. 1. Only three studies qualified for inclusion, with little consistency in their outcome measures [19-21]. This heterogeneity meant that aside from 
Fig. 1 Flow diagram of literature search, including the results of the study selection strategy, numbers screened and excluded at each stage and reasons for full-text article exclusion
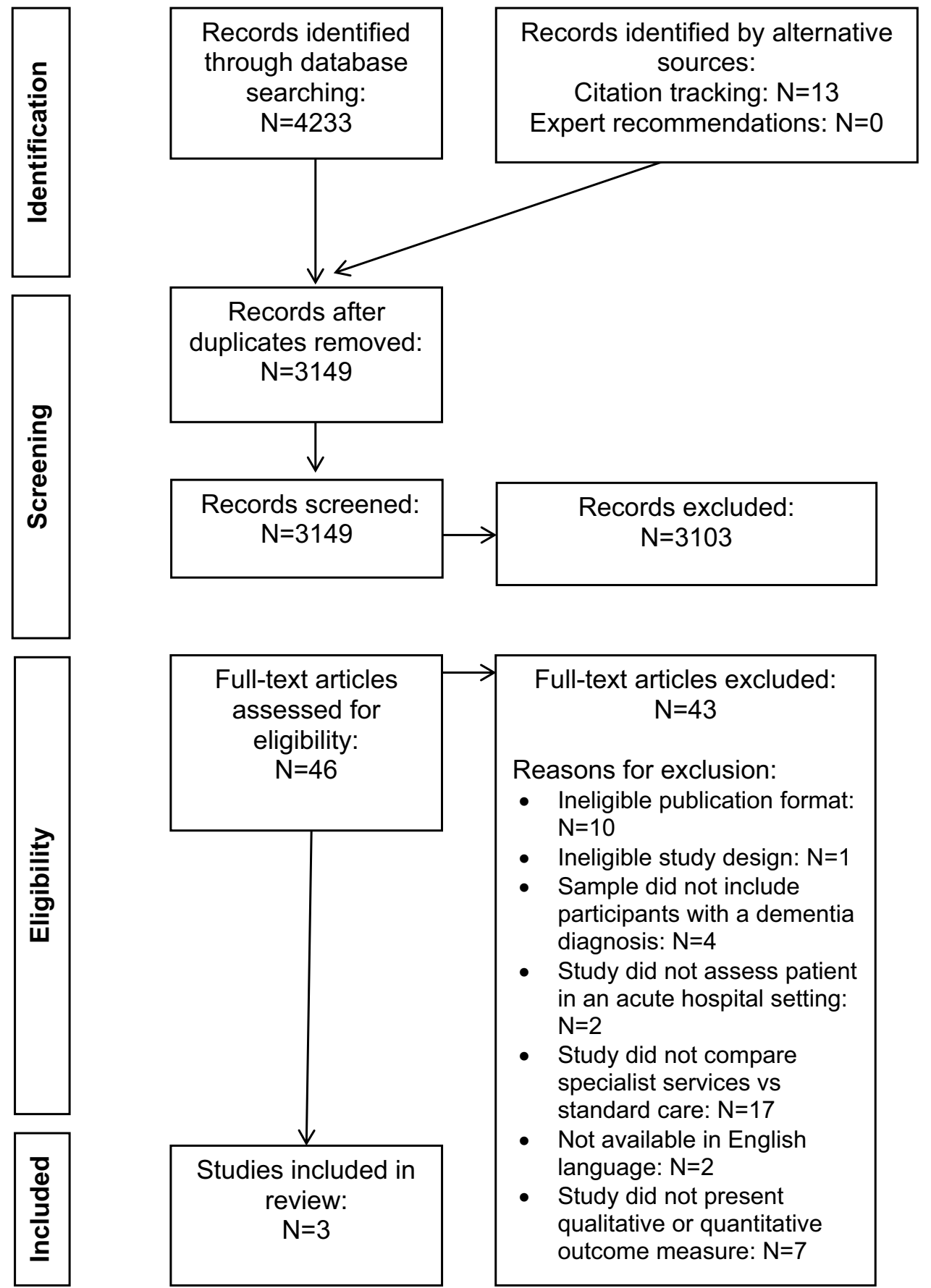

mortality, the data were not suitable to pool for meta-analysis. A narrative synthesis of the remaining data was performed. The study characteristics are summarised in Table 1. Simplified schematic results for comparison are given in Table 2; excluding the study by Spencer et al. [19] as their qualitative results could not be similarly summarised. The combined result for the critical appraisal is included in Table 1. None of the included studies were excluded for scoring poorly on quality.

\section{Results synthesis}

Only LOS, rates of BPSD and mortality were measured by more than one study. From these, only mortality data allowed the generation of odds ratios and a Forest plot, Fig. 2. No significant difference was found in mortality between the SIDU and SWC in either study; Briggs et al. [20] (SIDU $9 \%$ vs. SWC $8 \%$, OR 1.21; CI 0.65-2.22; $P=0.55$ ); Goldberg et al. [21] (22\% SIDU vs. $25 \%$ for SWC; OR 0.87; CI 


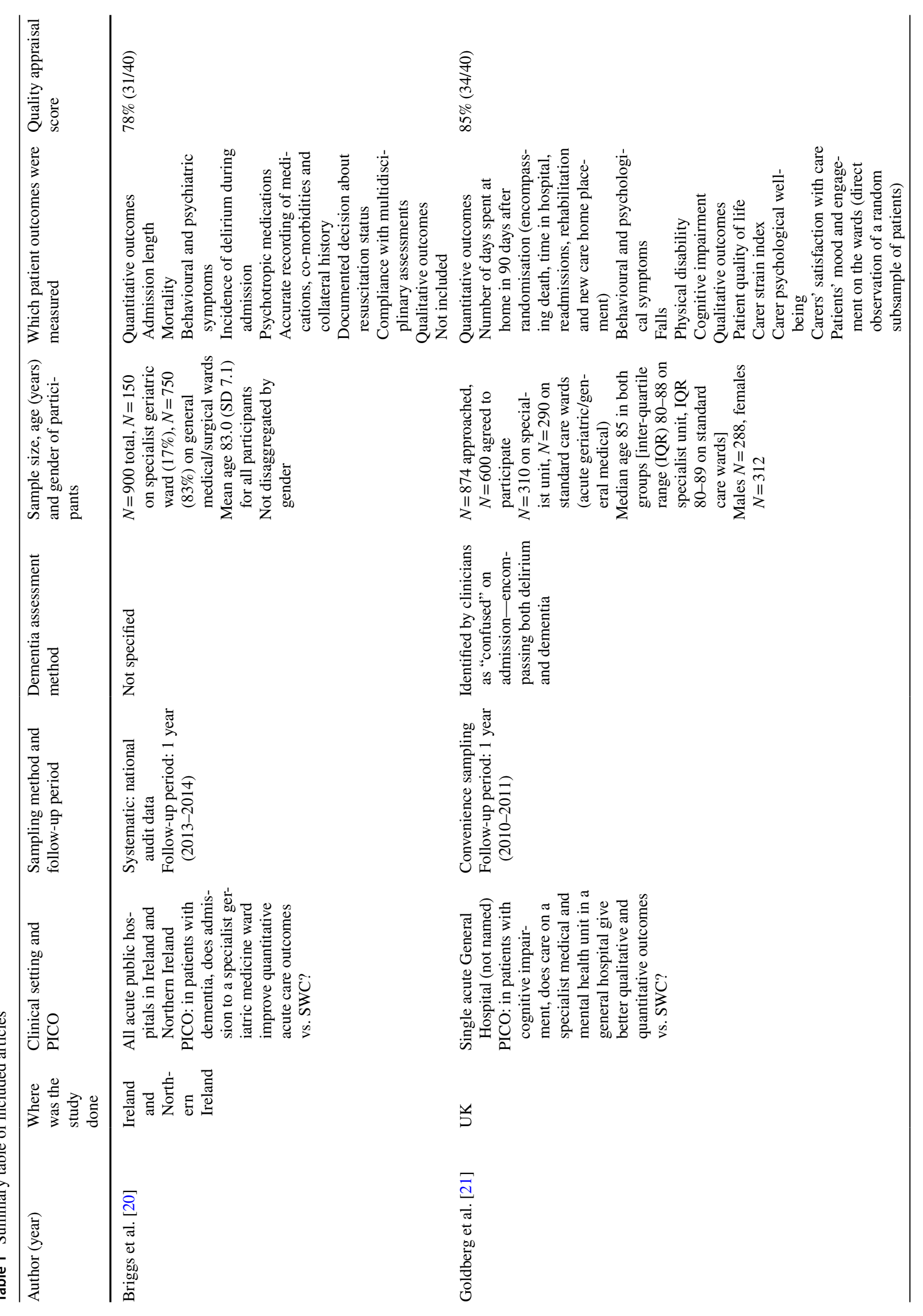




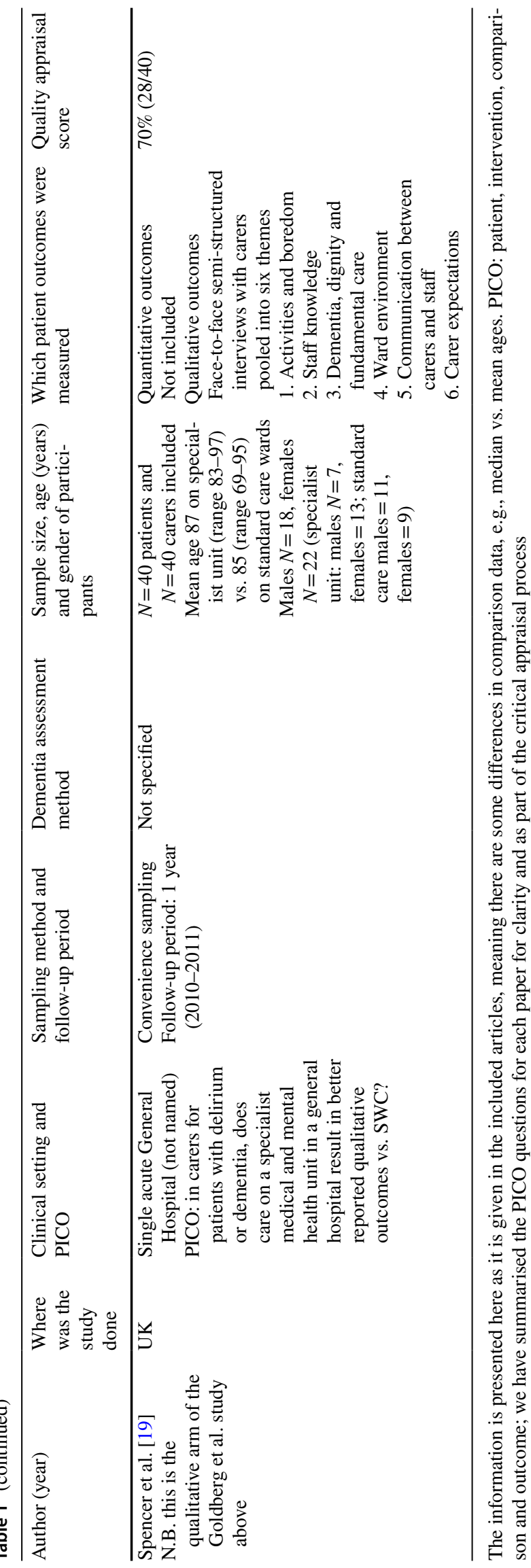

$0.60-1.23 ; P=0.46)$. The pooled odds ratio was 1.06 (CI $1.0-1.4)$.

Neither quantitative study found a significant difference in LOS between the SIDU and SWC (SIDU 28.5 \pm 31.4 days vs. SWC $25.1 \pm 38.7, P=0.471$ ) [22]; (SIDU 16 vs. SWC 16 median days; adjusted CI 0.93-1.23, $P=0.32$ ) [21]. However, Briggs et al. [20] found that fewer admissions on the SIDU lasted less than 7 days (SIDU $22.0 \%$ vs. SWC $28.3 \%$, $P=0.250$ ) and Goldberg et al. [21] found that the SIDU had a non-significantly lower rate of readmission (32 vs. $35 \%$ for SWC; CI -10 to $5 \%$ ). Neither study found that rates of BPSD varied significantly between SIDU and SWC; SIDU $30 \%$ vs. SWC $24 \%$, (OR 1.36; CI 0.88-2.10) [22]; SIDU 18.5 vs. SWC 17 , median number of recorded symptoms at 90 days $(\mathrm{CI}-5$ to $7.5, P=0.77)$ [21].

\section{Quantitative outcomes}

Briggs et al. [20] found the incidence of delirium was slightly greater on SIDU (SIDU 46 vs. 33\%, OR 1.70; CI 1.14-2.53), as was the rate of new prescriptions of antipsychotic medications (SIDU 50\% vs. SWC 34\%, OR 1.95; CI 1.08-3.51). Overall antipsychotic prescription rate differences between the wards were non-significant (SIDU 37\% vs. SWC 38\%, OR 0.96; CI 0.66-1.38) and there was little difference between the wards in documenting the reasoning behind the prescriptions (SIDU 60\% vs. SWC 59\%, OR; CI 0.55-1.98). SIDU patients more often had an accurate drug history documented (SIDU 97\% vs. SWC 89\%, OR 3.55; CI 1.41-8.92), accurate co-morbidities listed (SIDU $81 \%$ vs. SWC 79\%, OR 1.62; CI 0.98-2.68) and had a recorded collateral history regarding cognitive impairment (SIDU 38 vs. $25 \%$, OR 1.85; CI 1.28-2.68). They were also more likely to have documented discharge plans (SIDU 66 vs. $45 \%$, OR 2.38; CI 1.58-3.60) and resuscitation status decisions (SIDU $39 \%$ vs. SWC $34 \%$, OR 1.23; CI 0.82-1.84).

Goldberg et al. [21] found no significant difference in days spent at home 90 days post randomisation (SIDU 51 vs. 45 days median for SWC; $\mathrm{CI}-12$ to $24, P=0.3$ ). SIDU patients were non-significantly more likely to be discharged to their original home (74 vs. $70 \%$ for SWC; CI -3 to $11 \%$ ) and less likely to go to a new care home (20 vs. $28 \%$ for SWC; CI -16 to $0 \%$ ). There were no significant differences in Barthel index scores for physical disability (mean scores: SIDU $11.6 / 20$ vs. $11.6 / 20$ for SWC; adjusted CI -1.1 to 0.8 , $P=0.78$ ) and Mini-Mental State Examination (MMSE) for cognitive impairment (SIDU 16/30 vs. SWC 16/30 median score; $\mathrm{CI}-4$ to $2, P=0.83$ ).

\section{Qualitative outcomes}

Goldberg et al. [21] found no significant difference at 90 days in patient's quality of life (QOL) using multiple 
Table 2 Schematic results summary

\begin{tabular}{|c|c|c|c|c|}
\hline \multirow[t]{2}{*}{ Outcome } & \multicolumn{2}{|c|}{$\begin{array}{l}\text { Briggs et al. } \\
{[20]}\end{array}$} & \multicolumn{2}{|c|}{$\begin{array}{l}\text { Goldberg } \\
\text { et al. [21] }\end{array}$} \\
\hline & SIDU & SWC & SIDU & SWC \\
\hline \multicolumn{5}{|l|}{ Quantitative } \\
\hline Length of stay & $\leftrightarrow$ & $\leftrightarrow$ & $\leftrightarrow$ & $\leftrightarrow$ \\
\hline Days spent at home & - & - & $\leftrightarrow$ & $\leftrightarrow$ \\
\hline Discharged to their own home & - & - & $\uparrow$ & $\downarrow$ \\
\hline Discharged to new care home & - & - & $\downarrow$ & $\uparrow$ \\
\hline Rate of readmission & - & - & $\downarrow$ & $\uparrow$ \\
\hline Mortality & $\leftrightarrow$ & $\leftrightarrow$ & $\leftrightarrow$ & $\leftrightarrow$ \\
\hline Rates of BPSD & $\leftrightarrow$ & $\leftrightarrow$ & $\leftrightarrow$ & $\leftrightarrow$ \\
\hline Incidence of delirium $^{\mathrm{a}}$ & $\uparrow$ & $\downarrow$ & - & - \\
\hline New antipsychotic medications ${ }^{\mathrm{a}}$ & $\uparrow$ & $\downarrow$ & - & - \\
\hline Overall antipsychotic prescription rates & $\leftrightarrow$ & $\leftrightarrow$ & - & - \\
\hline Documentation of treatment decisions & $\leftrightarrow$ & $\leftrightarrow$ & - & - \\
\hline Accurate drug history ${ }^{\mathrm{a}}$ & $\uparrow$ & $\downarrow$ & - & - \\
\hline Accurate co-morbidities documented ${ }^{\mathrm{a}}$ & $\uparrow$ & $\downarrow$ & - & - \\
\hline $\begin{array}{l}\text { Collateral history taken regarding } \\
\text { cognition }^{\mathrm{a}}\end{array}$ & $\uparrow$ & $\downarrow$ & - & - \\
\hline Single plan for discharge ${ }^{\mathrm{a}}$ & $\uparrow$ & $\downarrow$ & - & - \\
\hline Resuscitation status documented $^{\mathrm{a}}$ & $\uparrow$ & $\downarrow$ & - & - \\
\hline Barthel index score & - & - & $\leftrightarrow$ & $\leftrightarrow$ \\
\hline MMSE score & - & - & $\leftrightarrow$ & $\leftrightarrow$ \\
\hline \multicolumn{5}{|l|}{ Qualitative } \\
\hline Patient quality of Life & - & - & $\leftrightarrow$ & $\leftrightarrow$ \\
\hline Carer strain index & - & - & $\leftrightarrow$ & $\leftrightarrow$ \\
\hline Carer psychological well-being & - & - & $\leftrightarrow$ & $\leftrightarrow$ \\
\hline Patient positive mood/engaged* & - & - & $\uparrow$ & $\downarrow$ \\
\hline Patient active & - & - & $\uparrow$ & $\downarrow$ \\
\hline Patient interacting with others socially & - & - & $\uparrow$ & $\downarrow$ \\
\hline
\end{tabular}

SIDU: Specialist Inpatient Dementia Units (as defined by the source papers). The symbols $\uparrow$ for more, $\downarrow$ for less and $\leftrightarrow$ for equivalent outcomes are used to summarise the results simply. A dash (-) is used to denote that this was not measured by the study

SWC standard ward care

${ }^{*} P$ value $<0.05$

${ }^{a}$ Odds ratio $>1$

measures, carer strain index (SIDU 5.7/13 vs. SWC 5.8/13; adjusted $\mathrm{CI}-0.49$ to $1.04, P=0.48$ ) or carer psychological well-being [SIDU 12.5 (GHQ-12-out of total 36) vs. SWC 12 (GHQ-12/36); adjusted CI 1.0-1.23, $P=0.05]$. More carers were happy with the care received on the SIDU (91\% satisfied overall vs. $83 \%$ on SWC, CI $2-15 \% ; P=0.004)$. However, both study groups included care givers who were very dissatisfied with the quality of care received. The highest percentages of very unsatisfied carer responses for both were around communication and keeping carers informed (SIDU $11 \%$ vs. SWC 17\% 'very unsatisfied') and discharge arrangements (SIDU 12\% vs. SWC 19\% 'very unsatisfied').
In a subsample of patients, mood and engagement was represented by the proportion of time that a behaviour was observed during the designated period; SIDU patients were significantly more often in a positive mood/engaged (SIDU $79 \%$ vs. SWC $68 \%$; CI $2-20, P=0.03$ ), with trends for being more active ( $82 \%$ SIDU vs. $74 \%$ SWC; CI -2 to 16 , $P=0.10)$ and interacting with others (47\% SIDU vs. $39 \%$ SWC; CI -3 to $19 ; P=0.06$ ).

Spencer et al. [19] performed a qualitative study of 40 carers' views of their experience of the Goldberg et al. [21] SIDU. The themes from semi-structured interviews included activities and boredom, staff knowledge, dementia, dignity and fundamental care, ward environment, communication between carers and staff and carer expectations. Carers of patients on SIDU commented their relatives were more often engaged in activities, whereas the SWC carers more often stated that their relatives had little to do. Staff on the SIDU were described as patient and compassionate with good knowledge of how to care for people with dementia, particularly regarding wandering and BPSD, displaying personalised support. This was the opposite for SWC, where carers felt the staff sometimes had negative attitudes towards dementia care, ignoring or shouting at the patients; particularly if they were showing challenging behaviours. Some carers felt they had to provide their relative one-to-one care as the ward staff were inexperienced.

Both carer groups had some negative comments about dignity and privacy, including inadequate personal hygiene care and lack of privacy when 'toileting'. Both groups were happy with the meals provided and efforts taken to offer alternatives if their relative had reduced appetite. However, neither was completely satisfied with the level of personal assistance given for eating and drinking. Both ward environments were felt to be clean, but the personalised touches on the SIDU were appreciated by the carers. Both SIDU and SWC carers wanted more communication with the ward staff; their main concern being feeling uninformed about their relatives' care and discharge. Both groups had positive experiences of interactions with the staff. However, poor relationships with staff or certain staff members were associated with greater general dissatisfaction with the level of care provided. It was commented that despite some measures being taken to understand patients' personal lives, particularly on the SIDU, the typically short LOS on acute wards made it difficult for staff to get to know their patients.

Overall, there was greater satisfaction with the level of care provided by the SIDU than by SWC. To address unmet expectations, carers were asked to suggest improvements. These included staff introducing themselves, increased stimulation for patients, allowing carers to attend ward rounds, extending visiting hours, using named nurses, daily updates from staff and having a separate bay for patients with more BPSD. 
Fig. 2 Forest plot odds estimates for mortality comparing SIDU with SWC. No significant difference was found by either in mortality between the SIDU and SWC; Briggs et al. [20] (SIDU 9\% vs. SWC 8\%, OR 1.21 ; CI 0.65-2.22; $P=0.55$ ); Goldberg et al. [21] (22\% SIDU vs. $25 \%$ for SWC; OR 0.87 ; CI $0.60-1.23 ; P=0.46)$. The pooled odds ratio for mortality was 1.06 (CI 1.0-1.4)

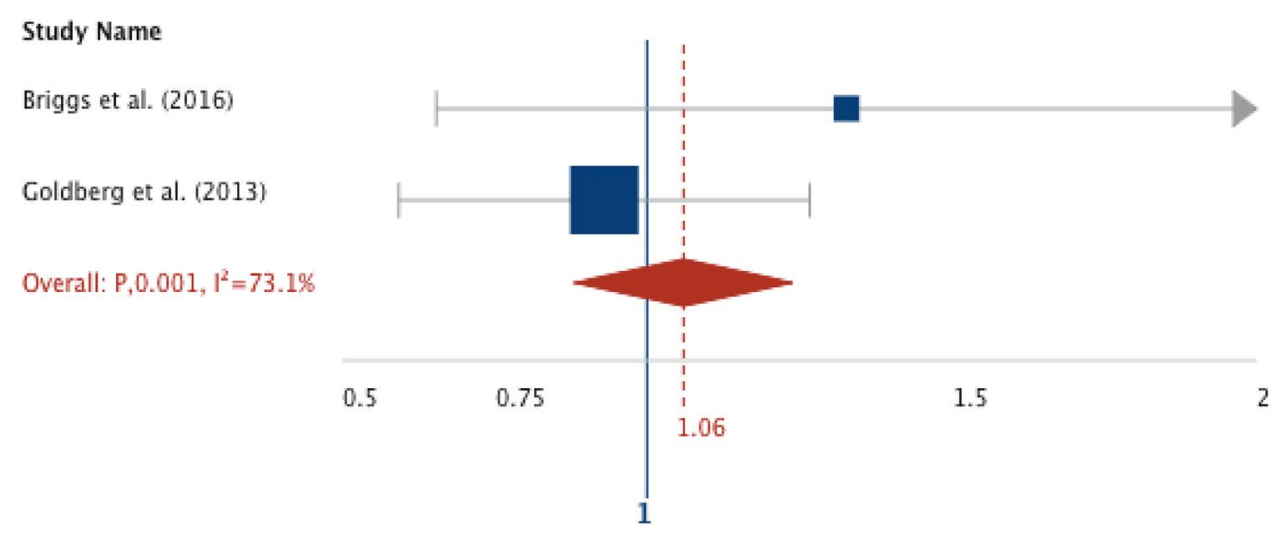

\section{Discussion}

The SIDU model of care has been developed within acute Trusts as a means to improve the quality of care delivered and optimise flow through the hospital for people with dementia. However, due to the limited number of eligible studies, this review found no significant differences in rates of BPSD, mortality and LOS between SIDU or SWC from either study measuring quantitative outcomes [20, 21]. As no other measure was used consistently across the eligible studies, the results of other quality and flow outcomes are from individual studies.

This review cannot be used to draw firm conclusions about SIDU care and whether they should be established more widely. Nevertheless, it appears that more patients are being discharged to their own homes from SIDU, fewer to care home placements and that SIDU are associated with lower rates of readmission to hospital. This clearly has benefits to the acute trust as well as to the health economy. The SIDU model is associated with better recorded plans for discharge and recording of drug, medical and collateral histories and of resuscitation decisions. The higher incidence of delirium and of new antipsychotic prescriptions on SIDU found by Briggs et al. [20] may reflect more accurate recognition and treatment of delirium on SIDU compared with SWC, possibly be due to differences in staff expertise. Goldberg et al. [21] found that patients on the SIDU were more often in a positive mood, active and interacting with others than SWC patients. Overall carers were more satisfied with the care received on the SIDU, although both SIDU and SWC groups generated areas for improvement, and neither showed quantitative difference in measures of long-term patient QOL or carer strain and psychological well-being [19].

\section{Critical appraisal}

All three original studies were limited by omitting the definition of dementia used to classify their participants. Briggs et al. [20] did not record the severity of dementia which may have confounded their results. They studied patients admitted from home rather than care homes, and used the prevalence of BPSD as a proxy measure for dementia severity, stating that as there was no significant baseline difference between groups, any confounders would be equally distributed and therefore not affect the analysis.

Briggs et al. [20] used retrospective data. This is reliant on accurate and thorough documentation of the care given throughout a patient's admission, which is often not completed. The authors argue that this is likely to be an issue for any similarly designed study and will have affected both SIDU and SWC equally, being therefore unlikely to significantly skew their results.

Goldberg et al. [21] and Spencer et al. [19] studies are generated from the same randomised controlled trial; the former presenting quantitative and qualitative outcomes from their entire study, the latter presenting the results of a smaller, more in-depth qualitative arm. Both studies were limited by differences between the groups at baseline due to pragmatically having to recruit participants after randomisation because of pressures on acute unit beds. This was adjusted for in the analysis, but may have introduced confounders.

Following up people with dementia is difficult as they are often frail and may move frequently between their home, healthcare systems and care placements. There are also ethical concerns relating to fluctuating capacity to consent to inclusion in a prolonged trial [21, 23, 24]. Goldberg et al. [21] used statistical imputation to address their missing follow-up data, a model which replaces the missing value(s) with an estimate based on known results [25]. Although this is an established method of minimising bias introduced by missing data, it would have been preferable to have the complete data set to increase the likelihood of statistically significant results [26].

As Briggs et al. [20] used data from a multi-centre systematic audit in Northern Ireland and Ireland, it is likely that their results are externally valid. However, the other two 
studies are from the same single hospital in the UK and so their results may not be generalisable.

\section{Strengths and limitations of this review}

This review expands on previous research assessing the efficacy and cost-effectiveness of SIDU. To our knowledge it is unique in being a systematic analysis and appraisal of this literature. The protocol was published on PROSPERO for transparency and replication, and PRISMA reporting guidelines were followed [13, 14]. The searches and quality appraisal were checked and performed by an independent reviewer to generate a more rigorous result. The data extraction and critical appraisal tools used are standardised and have been piloted previously, with good reliability [27]. Direct correspondence with experts ensured we had not missed unpublished, potentially eligible studies.

Publication and reporting bias may have affected our results as we did not include non-English language studies, and due to the general preferential publication of studies with positive results [28]. This review is limited by the lack of studies eligible for inclusion, meaning we are not able to infer direction of causality between SIDU and outcomes, or make definitive conclusions about the relative advantages or disadvantages of SIDU.

\section{Conclusion and future research}

Although there is little consistent evidence that SIDU are superior to SWC, this more person-focused form of clinical care for people with dementia appears to be associated with greater patient and carer satisfaction, possible reduced readmission rates, more accurate history taking and documentation of resuscitation decisions and increased rates of discharge to the patients' own home. Although mortality data was comparable, SIDU may represent a higher quality model of care for patients living with dementia.

Acute Trusts need to develop and demonstrate 'gold standard' dementia care models. Whilst quantitative measures such as LOS are important in evaluating service delivery, qualitative assessments are vital in ascertaining broader aspects of clinical care such as maintenance of dignity and autonomy.

The surprising paucity in eligible studies of SIDU directly contradicts the growing number of older people living with dementia admitted acutely. Hospitals nationwide need to develop innovative ways to provide high-quality specialist dementia care in line with NHS and Royal College standards, whilst maintaining flow and avoiding inappropriate readmissions [29]. It is vital to publish more research and service evaluation in this area.

\section{Relevance to key groups}

These findings are relevant to any involved in developing dementia services, from healthcare workers to commissioning groups and policy makers.

\section{Summary}

- What is known already:

- Dementia in acute NHS hospitals is a growing challenge which needs to be addressed to meet the increasing need

- SIDU have been developed to tackle the health inequalities experienced by people with dementia during acute admissions

- What this review adds:

- $\quad$ Despite limited eligible studies, we can infer that some outcomes are improved by SIDU, such as lower rates of admission to a care home, rates of readmission and of failed discharge from hospital

- What needs to be further investigated:

- $\quad$ There needs to be further investigation of the efficacy and acceptability of these SIDU if they are being offered as a method nationally for improving dementia care in acute NHS Trusts

- Our future research aims:

We will conduct a service evaluation of our new SIDU ('Enhanced Dementia Care Ward') as informed by this review, evaluating dementia care by comparing the SIDU with general medicine and geriatric ward care in a busy Tertiary Care Centre in Southampton, UK.

Acknowledgements We would like to thank Professor Helen Roberts and Dr Kylee Trevillion for their help and contributions towards this review.

Author contributions BM, KL, JA, DSB and VOH were involved in the conceptualisation of this review. BM performed the searches, study selection, analysis, critical appraisal and drafted the manuscript. $\mathrm{VOH}$ checked $10 \%$ of the searches and independently performed the critical appraisal. BM, JA, HPP and VOH edited the drafts and all authors read and approved the final version of this manuscript.

\section{Compliance with ethical standards}

Conflict of interest The authors declare that they have no conflict of interest. HPP is supported by the National Institute for Health Research (NIHR) through the NIHR Southampton Biomedical Research Centre. No funding grants were used for this review. There were no competing interests from any of the authors in the completion of this manuscript. There are no additional data for access. 
Ethical approval This article does not contain any studies with humanparticipants performed by any of the authors.

Informed consent For this type of study formal consent is not required.

Open Access This article is distributed under the terms of the Creative Commons Attribution 4.0 International License (http://creativeco mmons.org/licenses/by/4.0/), which permits unrestricted use, distribution, and reproduction in any medium, provided you give appropriate credit to the original author(s) and the source, provide a link to the Creative Commons license, and indicate if changes were made.

\section{Appendix 1: Search terms for replication of review}

This example was used on the Psychinfo database: exp dementia/ or *"alzheimer's disease"/ or *"cognitive impairment"/ or *"vascular dementia"/ or *"senile dementia"/ or *"dementia with lewy bodies"/ or ("dementia" or "amnestic, cognitive disorders" or "alzheimer" or "ad" or "lewy body" or dlb or lbd or ftd or ftld or "frontotemporal lobar degeneration" or "frontotemporal dementia" or "cognitive impairment" or "memory complaint, decline or disorder").ti,ab) and (exp "health care services"/ or (exp "quality of care"/ or exp "health care services"/ or exp "health care delivery"/ or exp "health service needs"/ or exp "integrated services"/ or exp "mental health programs"/ or exp "quality of services"/))) and (acute hospital).ti,ab".

\section{Appendix 2: Checklist and data extraction form}

Study Type:

Author Name:

Paper title:

Reviewer ID: 


\section{Checklist}

Does the paper meet each of the following inclusion criteria?

\begin{tabular}{|l|l|}
\hline Inclusion criteria & $\begin{array}{l}\text { If yes tick } \\
\text { box }\end{array}$ \\
\hline $\begin{array}{l}\text { Study is published in a peer-reviewed journal, report, or is a } \\
\text { thesis/dissertation. }\end{array}$ & \\
\hline $\begin{array}{l}\text { Study uses an eligible study design (randomised controlled trial, non- } \\
\text { randomised controlled trial, parallel group study, before and after study, } \\
\text { interrupted time series, cohort study, case-control study, case review, } \\
\text { cross-sectional study, qualitative interview, focus group interviews) }\end{array}$ & \\
\cline { 2 - 3 } Case series will be kept for separate analysis & \\
\hline Sample includes participants aged 16 years or older & \\
\hline $\begin{array}{l}\text { Sample includes participants with dementia } \\
\text { Sample includes participants who are inpatients of an acute hospital } \\
\text { (including Emergency Department setting, mental healthcare setting (only } \\
\text { as part of an acute Trust liaison inpatient setting), acute hospital/medical } \\
\text { services, inpatient acute hospital Neurology services, other acute Trust } \\
\text { healthcare setting) }\end{array}$ & \\
\hline $\begin{array}{l}\text { Study compares specialist dementia services versus standard care in } \\
\text { acute hospitals }\end{array}$ & \\
\hline $\begin{array}{l}\text { Study results include qualitative or quantitative outcome measures of } \\
\text { patient and/or carer experience of the hospital stay. }\end{array}$ & \\
\hline
\end{tabular}

If the paper does not meet all of the above criteria, please indicate below the reasons why:

\begin{tabular}{|l|l|}
\hline Exclusion criteria & $\begin{array}{l}\text { If yes tick } \\
\text { box }\end{array}$ \\
\hline $\begin{array}{l}\text { Study is published in a book, conference paper, general comment paper, } \\
\text { letter, editorial or other non-peer reviewed format. }\end{array}$ & \\
\hline Study uses an ineligible study design (e.g. single case study) & \\
\hline $\begin{array}{l}\text { Sample is aged 15 or younger (or includes participants aged 15 or } \\
\text { younger and does not provide appropriately disaggregated data) }\end{array}$ & \\
\hline Sample does not include participants with a diagnosis of dementia & \\
\hline Study does not measure appropriate patient outcome measures & \\
\hline $\begin{array}{l}\text { Study does not compare specialist dementia services versus standard } \\
\text { care in acute hospitals }\end{array}$ & \\
\hline $\begin{array}{l}\text { Study does not use patients from an acute hospital setting (Non-clinical } \\
\text { setting, Primary healthcare setting, Mental healthcare setting (community } \\
\text { mental health setting), Mental healthcare setting (outpatient unit), Mental } \\
\text { healthcare setting (inpatient unit), outpatient Memory Clinic/ Dementia } \\
\text { services, Residential Care/Retirement/Nursing home, Not specified }\end{array}$ & \\
\hline
\end{tabular}

If the paper meets any of the exclusion criteria do not proceed any further. 


\section{Data extraction}

\section{Study design}

Please enter the dates of data collection:

\begin{tabular}{|l|l|}
\hline Year of start of data collection & \\
\hline Year of end of data collection & \\
\hline
\end{tabular}

Please select the study design:

\begin{tabular}{|l|l|l|}
\hline Study Type & If yes tick box(es) & Please specify if required \\
\hline Randomised controlled trial & & \\
\hline $\begin{array}{l}\text { Non-randomised controlled } \\
\text { study }\end{array}$ & & \\
\hline Parallel group studies & & \\
\hline Before and after studies & & \\
\hline Interrupted time series studies & & \\
\hline Cohort Study & & \\
\hline Case review & & \\
\hline Case Control Study & & \\
\hline Cross Sectional Study & & \\
\hline Qualitative interview & & \\
\hline Focus group interviews & & \\
\hline Other (please specify): & & \\
\hline
\end{tabular}

Please select the study sample type:

\begin{tabular}{|l|l|l|}
\hline Study Setting & $\begin{array}{l}\text { If yes tick } \\
\text { box(es) }\end{array}$ & Please specify if required \\
\hline Emergency Department setting & & \\
\hline $\begin{array}{l}\text { Mental healthcare setting (inpatient liaison } \\
\text { service as part of acute Trust) }\end{array}$ & & \\
\hline Acute hospital/medical services & & \\
\hline Acute neurology services & & \\
\hline $\begin{array}{l}\text { Other acute healthcare setting (please } \\
\text { specify): }\end{array}$ & & \\
\hline
\end{tabular}

Please select the sampling method used in the study:

\begin{tabular}{|l|l|l|}
\hline Sampling Method & $\begin{array}{l}\text { If yes, tick } \\
\text { box(es) }\end{array}$ & Specify if required \\
\hline Random sampling & & \\
\hline Systematic sampling & & \\
\hline Stratified sampling & & \\
\hline Convenience sampling & & \\
\hline $\begin{array}{l}\text { Matched sampling (please provide } \\
\text { details) }\end{array}$ & & \\
\hline Quota sampling & & \\
\hline Other (please specify) & & \\
\hline Not specified & & \\
\hline
\end{tabular}




\section{Study population}

Please enter the number of males and females in the study sample:

\begin{tabular}{|l|l|}
\hline Sex & N \\
\hline Males & \\
\hline Females & \\
\hline Not specified & \\
\hline
\end{tabular}

Please enter details of the age of the study sample:

\begin{tabular}{|l|l|}
\hline & Age (yrs) \\
\hline Youngest & \\
\hline Oldest & \\
\hline Mean & \\
\hline Standard deviation & \\
\hline Not specified & \\
\hline
\end{tabular}

Please enter the study's inclusion criteria:

Please enter the study's exclusion criteria:

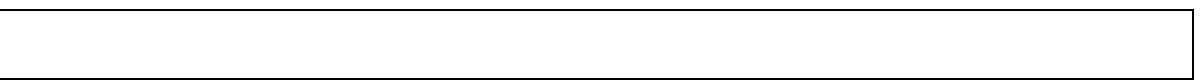

Please enter information about response rate:

\begin{tabular}{|l|l|}
\hline Number approached to participate & \\
\hline Number who agreed to participate & \\
\hline Not specified & \\
\hline
\end{tabular}

Please enter any comments about response rate: 


\section{Dementia}

Please enter the definition of dementia used in this study:

Please select the categories of dementia recorded for the sample (tick as many as apply and provide further detail if available):

\begin{tabular}{|c|c|c|c|}
\hline $\begin{array}{l}\text { Category of Dementia } \\
\text { (ICD 10) [DSM-5] }\end{array}$ & $\begin{array}{l}\text { If yes } \\
\text { tick } \\
\text { box(es) }\end{array}$ & $\begin{array}{l}\text { Provide further detail } \\
\text { if available (e.g., } \\
\text { specific diagnostic } \\
\text { code) }\end{array}$ & $\begin{array}{l}\text { Please indicate } \\
\text { whether disorder was } \\
\text { assessed with a } \\
\text { diagnostic or } \\
\text { screening instrument }\end{array}$ \\
\hline $\begin{array}{l}\text { Major Neurocognitive } \\
\text { Disorder [possible 331.9; } \\
\text { probable 294.1x] }\end{array}$ & & & \\
\hline $\begin{array}{l}\text { Mild Neurocognitive } \\
\text { Disorder [331.83] }\end{array}$ & & & \\
\hline $\begin{array}{l}\text { Dementia in Alzheimer's } \\
\text { disease (F00) [331.0] }\end{array}$ & & & \\
\hline $\begin{array}{l}\text { Vascular Dementia (F01) } \\
{[290.40]}\end{array}$ & & & \\
\hline $\begin{array}{l}\text { Dementia in other diseases } \\
\text { classified elsewhere (F02) }\end{array}$ & & & \\
\hline $\begin{array}{l}\text { Dementia in Pick's disease } \\
\text { (F02.0) }\end{array}$ & & & \\
\hline $\begin{array}{l}\text { Dementia in Creutzfeldt- } \\
\text { Jakob disease (F02.1) }\end{array}$ & & & \\
\hline $\begin{array}{l}\text { Dementia in Huntington's } \\
\text { disease (F02.2)[333.4] }\end{array}$ & & & \\
\hline $\begin{array}{l}\text { Dementia in Parkinson's } \\
\text { disease (F02.3)[332.0] }\end{array}$ & & & \\
\hline $\begin{array}{l}\text { Dementia in human } \\
\text { immunodeficiency virus } \\
\text { disease (F02.4)[042] }\end{array}$ & & & \\
\hline $\begin{array}{l}\text { Dementia in other specified } \\
\text { diseases classified } \\
\text { elsewhere (F02.8) }\end{array}$ & & & \\
\hline $\begin{array}{l}\text { Frontotemporal Lobar } \\
\text { Degeneration [331.19] }\end{array}$ & & & \\
\hline $\begin{array}{l}\text { Lewy Body Disease } \\
\text { [331.82] }\end{array}$ & & & \\
\hline $\begin{array}{l}\text { Traumatic Brain Injury } \\
\text { [907.0] }\end{array}$ & & & \\
\hline Prion disease [046.79] & & & \\
\hline $\begin{array}{l}\text { Unspecified dementia (F03) } \\
\text { [799.59] }\end{array}$ & & & \\
\hline Other (please specify) & & & \\
\hline Not specified & & & \\
\hline
\end{tabular}

If specified, please enter the dementia assessment measure used for this study:

Please select the criteria against which dementia is assessed:

\begin{tabular}{|l|l|l|}
\hline Criteria & $\begin{array}{l}\text { If yes tick } \\
\text { box(es) }\end{array}$ & Specify if required \\
\hline ICD-10 (or earlier versions) & & \\
\hline DSM-5 (or earlier versions) & & \\
\hline Not specified & & \\
\hline
\end{tabular}




\section{Outcomes}

Please select whether outcome measures are qualitative or quantitative (tick as many as apply):

\begin{tabular}{|l|l|}
\hline Qualitative & \\
\hline Quantitative & \\
\hline Not specified & \\
\hline
\end{tabular}

Please state what measure of patient outcome was used (tick as many as apply)

\begin{tabular}{|l|l|}
\hline Admission length & \\
\hline Access to services & \\
\hline Patient reported outcomes & \\
\hline Carer reported outcomes & \\
\hline Cost to Trust & \\
\hline Mortality & \\
\hline Psychotropic medications started & \\
\hline Readmissions & \\
\hline $\begin{array}{l}\text { Discharge care needs assessment/ } \\
\text { discharge planning and discussion }\end{array}$ & \\
\hline Other (please specify) & \\
\hline
\end{tabular}

If specified, please enter any additional information about patient outcome measures provided by this study:

Please enter any notes about these outcomes (e.g., are disaggregated figures available for analysis, were odds ratios adjusted?)

Please enter the following raw data:

\begin{tabular}{|l|l|}
\hline Total number of people included in the analysis & \\
\hline $\begin{array}{l}\text { Total number of people with dementia in specialist } \\
\text { wards/using specialist dementia care }\end{array}$ & \\
\hline $\begin{array}{l}\text { Total number of people without dementia in general } \\
\text { medical or surgical wards }\end{array}$ & \\
\hline
\end{tabular}

** Please repeat the outcomes section if you have further estimates for subgroups**

Please enter any further comments not covered elsewhere:

\section{Appendix 3: Quality appraisal form}

The critical appraisal tool for prevalence studies, developed by Loney et al. [17], incorporates a number of sources on study methodology from the Critical Appraisal Skills Programme checklists, sources on confounding and attrition and on quality rating of diagnosis ascertainment Downs, Black [16-18].
Please complete part 1 for all study designs and complete the relevant sections for part 2, specific to study design.

Score the answer to each question by ticking 0,1 or 2 :

0 - study does not meet criteria/answer question

1 - Study partially meets criteria/gives a partially satisfactory answer to the question

2-Study fully meets criteria/gives a fully satisfactory answer to the question 
Measurement of risk of reporting bias

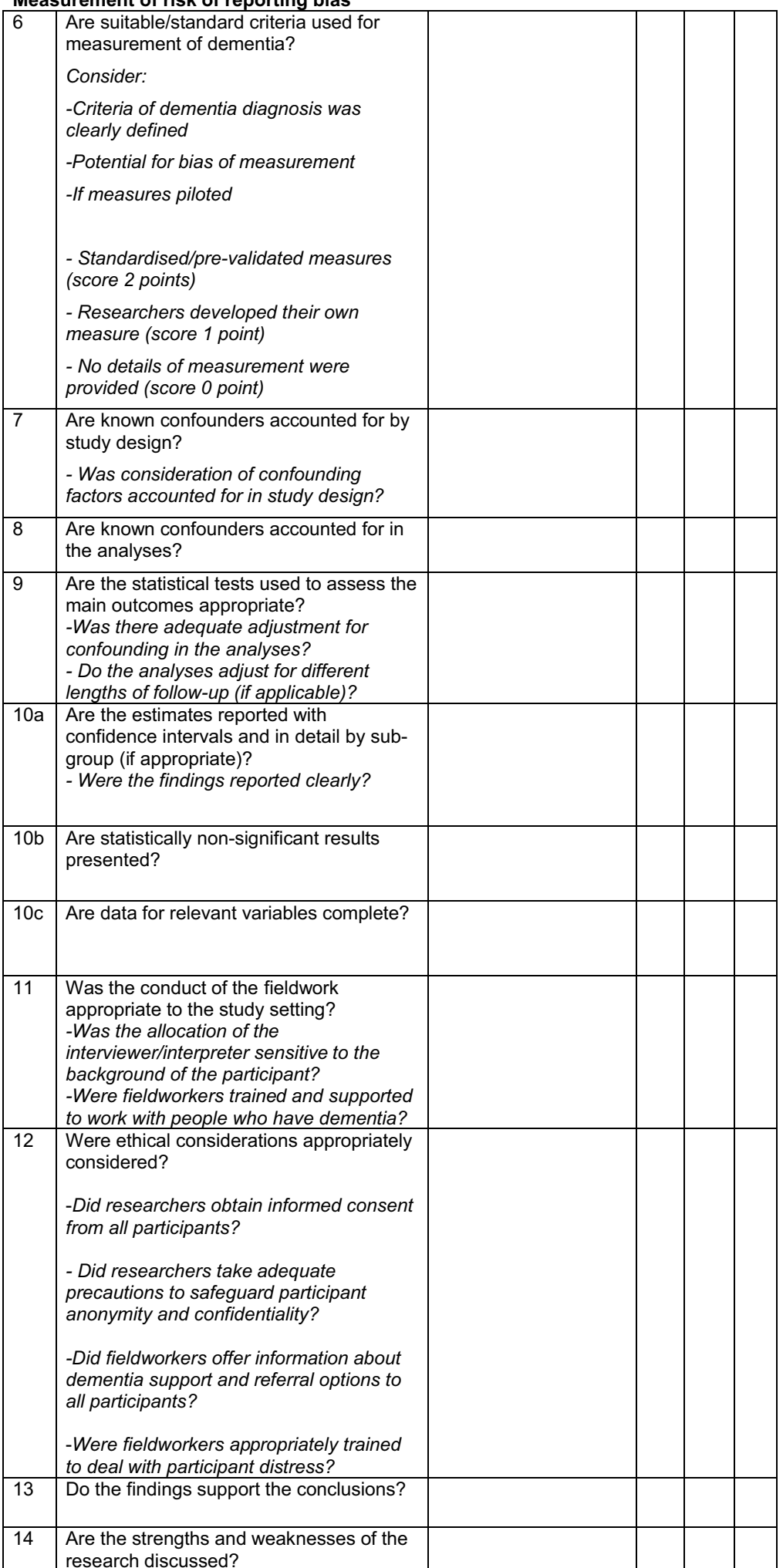

Calculate total score (out of a possible total of 40 ): 


\section{References}

1. Parkin E, Baker C (2018) Dementia: policy, services and statistics. Briefing paper Number 07007, 10 July 2018, House of Commons Library. Available from http://researchbriefings.files.parliament .uk/documents/SN07007/SN07007.pdf (original 2016 version of this source Accessed Dec 2017, updated document Accessed Sept 2018)

2. Department of Health (2015) Prime Minister's challenge on dementia 2020. GOV.UK, Cabinet Office, London

3. National Health Service England (2017) Dementia. Available from https://www.england.nhs.uk/mental-health/dementia/. Accessed Dec 2017

4. Prince M, Knapp M, Guerchet M, McCrone P, Prina M, ComasHerrera A, Wittenberg R, Adelaja B, Hu B, King D, Rehill A, Salimkumar D (2014) Dementia UK: Update, 2nd edn. Alzheimer's Society, London

5. National Health Service England (2017) Dementia assessment and referral data collection-Q2 2017-18. Available from https:// www.england.nhs.uk/statistics/2017/12/06/dementia-assessment -and-referral-data-collection-q2-2017-18/. Accessed Dec 2017

6. Reynish EL, Hapca SM, De Souza N, Cvoro V, Donnan PT, Guthrie B (2017) Epidemiology and outcomes of people with dementia, delirium, and unspecified cognitive impairment in the general hospital: prospective cohort study of 10,014 admissions. BMC Med 15:140. https://doi.org/10.1186/s12916-017-0899-0

7. O'Shea E, Manning E, Ross E, McErlean S, Timmons S (2015) Northern Ireland audit of dementia care in Acute Hospitals. Northern Ireland Audit of Dementia, Cork

8. Harwood R, Porock D, King N, Edwards G, Hammond S, Howe L, Russell C, Howard S, Jones R, Morrant J (2010) Development of a specialist medical and mental health unit for older people in an acute general hospital. University of Nottingham Medical Crises in Older People. Discussion paper series. ISSN 2044-4230. Available from https://www.nottingham.ac.uk/mcop/documents/ papers/issue5-mcop-issn2044-4230.pdf. Accessed Dec 2017

9. Royal College of Psychiatrists (2005) Who cares wins: improving the outcome for older people admitted to the general hospital: guidelines for the development of Liaison Mental Health Services for older people. Report of a Working Group for the Faculty of Old Age Psychiatry, Royal College of Psychiatrists. ISBN 085316 253 0. Available from https://www.rcpsych.ac.uk/pdf/whocareswi ns.pdf. Accessed Dec 2017

10. Digby R, Lee S, Williams A (2017) The experience of people with dementia and nurses in hospital: an integrative review. J Clin Nurs 26:1152-1171. https://doi.org/10.1111/jocn.13429

11. Moonga J, Likupe G (2016) A systematic literature review on nurses' and health care support workers' experiences of caring for people with dementia on orthopaedic wards. J Clin Nurs 25:1789_ 1804. https://doi.org/10.1111/jocn. 13158

12. Lakey L (2009) Counting the cost: caring for people with dementia on hospital wards. Alzheimer's Society. Available from https ://www.alzheimers.org.uk/sites/default/files/2018-05/Counting_ the_cost_report.pdf. Accessed Dec 2017

13. Moher D, Liberati A, Tetzlaff J, Altman DG (2009) Preferred reporting items for systematic reviews and meta-analyses: the PRISMA statement. PLoS Med 6:e1000097. https://doi. org/10.1371/journal.pmed.1000097

14. Stroup DF, Berlin JA, Morton SC, Olkin I, Williamson GD, Rennie D, Moher D, Becker BJ, Sipe TA, Thacker SB (2000) Metaanalysis of observational studies in epidemiology: a proposal for reporting. Meta-analysis of observational studies in epidemiology (MOOSE) group. JAMA 283:2008-2012

15. Fage BA, Seitz DP, Gill SS, Herrmann N, Smailagic N, Chan $\mathrm{CCH}$, Nikolaou V (2013) Mini-Cog for the diagnosis of
Alzheimer's disease dementia and other dementias within a community setting (Protocol). Cochrane Database Syst Rev. https:// doi.org/10.1002/14651858.CD010860

16. Downs SH, Black N (1998) The feasibility of creating a checklist for the assessment of the methodological quality both of randomised and non-randomised studies of health care interventions. J Epidemiol Community Health 52:377-384

17. Loney PL, Chambers LW, Bennet KJ, Roberts JG, Stratford PW (2000) Critical appraisal of the health research literature: prevalence or incidence of a health problem. Chronic Dis Can 19:170-177

18. Saha S, Chant D, Welham J, McGrath J (2005) A systematic review of the prevalence of schizophrenia. PLoS Med 2:e141

19. Spencer K, Foster P, Whittamore KH, Goldberg SE, Harwood RH (2013) Delivering dementia care differently-evaluating the differences and similarities between a specialist medical and mental health unit and standard acute care wards: a qualitative study of family carers' perceptions of quality of care. BMJ Open. https:// doi.org/10.1136/bmjopen-2013-004198

20. Briggs R, O'Neill D, Kennelly SP, O'Shea E, De Siun A, Gallagher P, Timmons S (2016) Does admission to specialist geriatric medicine wards lead to improvements in aspects of acute medical care for patients with dementia? Int J Geriatr Psychiatry 32:624-632

21. Goldberg SE, Bradshaw LE, Kearney FC, Russell C, Whittamore KH, Foster PE, Mamza J, Gladman JR, Jones RG, Lewis SA, Porock D, Harwood RH (2013) Care in specialist medical and mental health unit compared with standard care for older people with cognitive impairment admitted to general hospital: randomised controlled trial (NIHR TEAM trial). BMJ 347:f4132. https://doi.org/10.1136/bmj.f4132

22. Briggs R, Coary R, Collins R, Coughlan T, O'Neill D, Kennelly SP (2016) Acute hospital care: how much activity is attributable to caring for patients with dementia? QJM 109:41-44. https://doi. org/10.1093/qjmed/hcv085

23. Kim SYH (2011) The ethics of informed consent in Alzheimer disease research. Nat Rev Neurol 7:410-414. https://doi. org/10.1038/nrneurol.2011.76

24. Alzheimer Europe (2011) Informed consent to dementia research. http://www.alzheimer-europe.org/Ethics/Ethical-issues-in-pract ice/2011-Ethics-of-dementia-research/Informed-consent-todementia-research. Accessed 4 Jan 2017

25. Kenward MG (2013) The handling of missing data in clinical trials. Clin Investig 3:241-250

26. Chan A-W, Altman DG (2005) Identifying outcome reporting bias in randomised trials on PubMed: review of publications and survey of authors. BMJ 330:753. https://doi.org/10.1136/bmj.38356 $.424606 .8 \mathrm{~F}$

27. Trevillion K, Oram S, Feder G, Howard LM (2012) Experiences of domestic violence and mental disorders: a systematic review and meta-analysis. PLoS One 7:e51740. https://doi.org/10.1371/ journal.pone.0051740

28. Dwan K, Altman DG, Arnaiz JA, Bloom J, Chan A-W, Cronin E, Decullier E, Easterbrook PJ, Von Elm E, Gamble C, Ghersi D, Ioannidis JPA, Simes J, Williamson PR (2008) Systematic review of the empirical evidence of study publication bias and outcome reporting bias. PLoS One 3:e3081. https://doi.org/10.1371/journ al.pone.0003081

29. National Health Service Improvement (2017) Dementia assessment and improvement framework. Available from https://impro vement.nhs.uk/resources/dementia-assessment-and-improvemen t-framework/. Accessed Dec 2017 